\title{
Cardiac Imaging After Ischemic Stroke or Transient Ischemic Attack
}

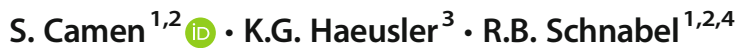

Published online: 30 June 2020

(C) The Author(s) 2020

\begin{abstract}
Purpose of Review Cardiac imaging after ischemic stroke or transient ischemic attack (TIA) is used to identify potential sources of cardioembolism, to classify stroke etiology leading to changes in secondary stroke prevention, and to detect frequent comorbidities. This article summarizes the latest research on this topic and provides an approach to clinical practice to use cardiac imaging after stroke. Recent Findings Echocardiography remains the primary imaging method for cardiac work-up after stroke. Recent echocardiography studies further demonstrated promising results regarding the prediction of non-permanent atrial fibrillation after ischemic stroke. Cardiac magnetic resonance imaging and computed tomography have been tested for their diagnostic value, in particular in patients with cryptogenic stroke, and can be considered as second line methods, providing complementary information in selected stroke patients.

Summary Cardiac imaging after ischemic stroke or TIA reveals a potential causal condition in a subset of patients. Whether systematic application of cardiac imaging improves outcome after stroke remains to be established.
\end{abstract}

Keywords Ischemic stroke $\cdot$ Transient ischemic attack $\cdot$ Echocardiography $\cdot$ Magnetic resonance imaging $\cdot$ Computed tomography $\cdot$ Embolism

\section{Abbreviations}

AF Atrial fibrillation

ASA Atrial septum aneurysm

CAD Coronary artery disease

CT Computed tomography

ECG Electrocardiogram

ESUS Embolic stroke of undetermined source

LA Left atrium/atrial

LAA Left atrial appendage

LV Left ventricle/ventricular

MI Myocardial infarction

This article is part of the Topical Collection on Stroke

R.B. Schnabel

r.schnabel@uke.de

1 Clinic for Cardiology, University Heart and Vascular Center Hamburg, Hamburg, Germany

2 DZHK (German Center for Cardiovascular Research) (partner site Hamburg/Kiel/Luebeck), Berlin, Germany

3 Department of Neurology, Universitätsklinikum Würzburg, Würzburg, Germany

4 University Heart Center Hamburg-Eppendorf, Martinistrasse 52, 20246 Hamburg, Germany
MRI Magnetic resonance imaging

OAC Oral anticoagulation

PFO Patent foramen ovale

TEE Transesophageal echocardiography

TIA Transient ischemic attack

TTE Transthoracic echocardiography

\section{Introduction}

Ischemic stroke etiology can be divided into five categories based on the TOAST criteria [1]: large artery atherosclerosis, cardioembolism, small vessel occlusion, stroke of other determined etiology, and stroke of undetermined ("cryptogenic") etiology. Cardioembolic stroke accounts for about 20-25\% of all ischemic strokes [2]. Sources for cardioembolism are further classified into major- or minor-risk sources according to their (thrombo-) embolic potential [3]. The most common major-risk source of cardioembolism is atrial fibrillation (AF) [4]. Less frequent major-risk sources are cardiomyopathies with left ventricular (LV) dysfunction, intracardiac thrombi, cardiac tumors, prosthetic valves, and endocarditis [3] (Fig. 1). Minor-risk sources include patent foramen ovale (PFO), atrial septum aneurysm (ASA), and calcification of aortic and mitral valve [3]. 


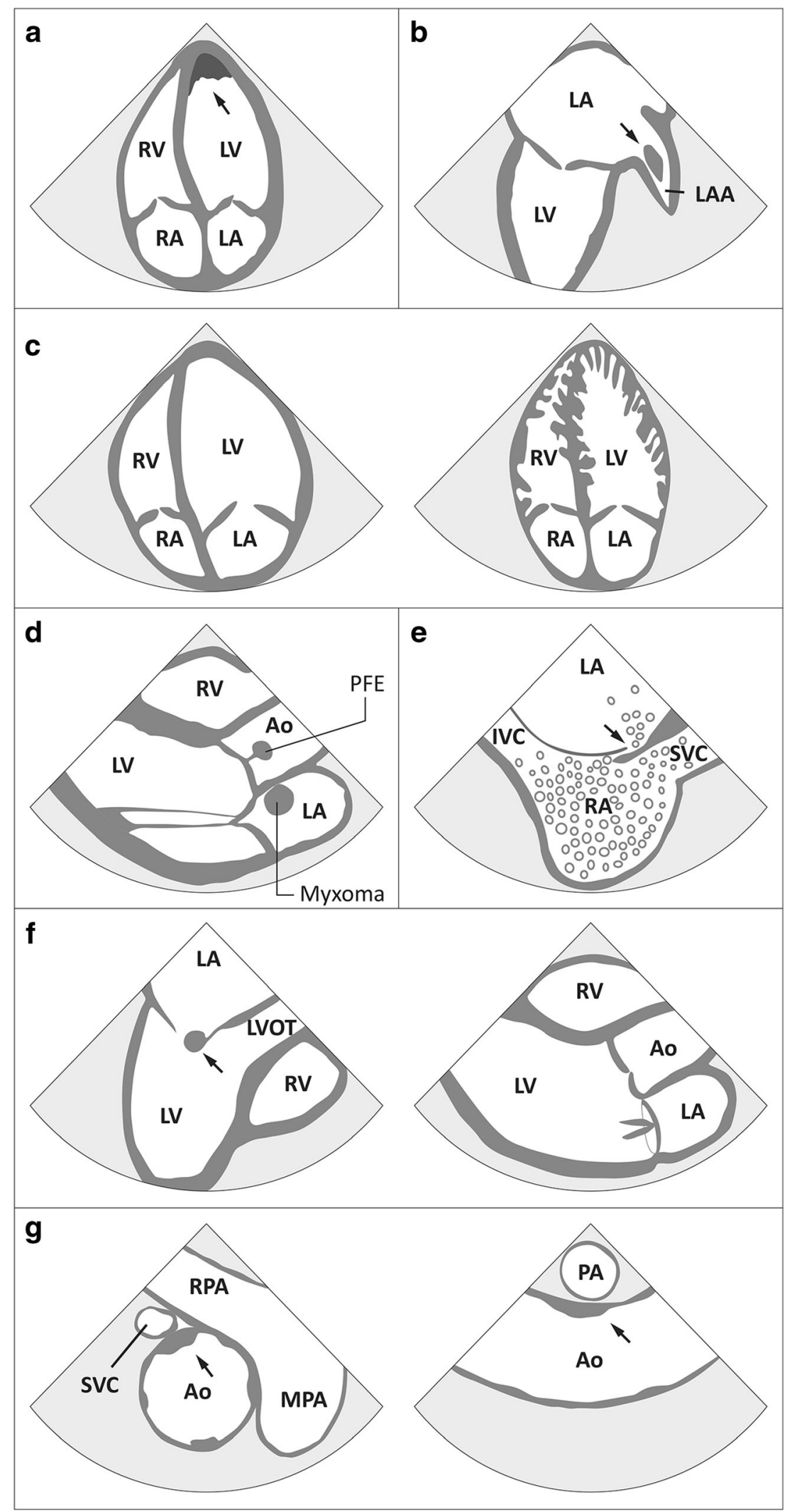

Transthoracic (TTE) and/or transesophageal echocardiography (TEE) are the standard methods for cardiac imaging after ischemic stroke $[5,6]$. In recent years, reports on the use of cardiac magnetic resonance imaging (MRI) and computed tomography (CT) after stroke have been increasingly published, particularly in patients with unknown stroke 
Fig. 1 Schematic presentation of the most frequent sources for cardiovascular embolism. a The most common localization of $L V$ thrombi, usually the result of regional akinesia due to a previous myocardial infarction, is the LV apex, which is ideally visualized on the apical 4-chamber view of the TTE. b Typical presentation of a $L A A$ thrombus on a TEE mid-esophageal 2-chamber view at about $90^{\circ}$. c Transthoracic apical 4-chamber-view demonstrating the pronounced dilation of the left ventricle in case of a dilated cardiomyopathy (left) and the multiple prominent ventricular trabeculations with intertrabecular spaces seen in non-compaction cardiomyopathy (right). d The usually valve associated papillary fibroelastoma (PFE) and myxoma, typically located in the atria, are the most common primary cardiac tumors in adults, which are both associated with a high risk of embolism (TTE parasternal long-axis view). e Bubble transition from the right to the left atrium (positive "bubble test") in case of a patent foramen ovale documented using a TEE mid-esophageal bicaval view at about $110^{\circ}$. f Vegetations, a main criterion for endocarditis (here mitral valve endocarditis diagnosed in a mid-esophageal longitudinal axis view of the left ventricle at about $120^{\circ}$ in the TEE examination; left), and prosthetic valves (here double-wing prosthesis of the mitral valve shown in a parasternal longitudinal axis view of the TTE; right) are further potential sources of cardioembolism. g Aortic atheroma $\geq 4 \mathrm{~mm}$ have been associated with ischemic stroke and can be detected during retraction of the TEE probe at the end of the examination (here midesophageal short (left) and long (right) axis view of the ascending aorta). Ao aorta, IVC inferior vena cava, LA left atrium, LAA left atrial appendage, LV left ventricle, LVOT left ventricular outflow tract, (M/R) PA (main/right) pulmonary artery, RA right atrium, RV right ventricle

etiology [7-10]. Cardiac work-up after stroke might lead to changes in secondary stroke prevention, guide screening for atrial fibrillation, and serve as a screening tool for (coronary) heart disease given the strong overlap of cerebrovascular and cardiovascular risk factors $[11,12]$. While screening for AF after stroke has become common practice, cardiac imaging after ischemic stroke is less well established $[4,11,13]$.

The purpose of this review is to summarize the available evidence, latest findings and guideline recommendations to guide physicians in the use of cardiac imaging after ischemic stroke or transient ischemic attack (TIA).

\section{Cardiac Imaging and Stroke Etiology}

The primary goal of cardiac imaging after stroke is to identify potential sources of embolism and subsequently establish stroke etiology. Due to the lack of prospective, randomized trials, the guideline recommendations for cardiac imaging after stroke differ considerably, resulting in a highly varying use of TTE and TEE across stroke centers [14]. Furthermore, the two most recent prospective studies comparing TTE and TEE in ischemic stroke patients were conducted in 2006 and yielded inconclusive results. In a prospective single-center study including 503 ischemic stroke patients, the incremental value of TEE over routine work-up (including TTE, carotid ultrasound, 12-lead electrocardiogram (ECG) and 24-h Holter-ECG in individuals with high suspicion for AF) was investigated [15]. Based on TEE findings, OAC was prescribed in $8 \%$ of 212 patients with so far cryptogenic ischemic stroke. However, in the vast majority of cases the indication for oral anticoagulation was at least debatable (e.g., aortic thrombi). Another prospective single-center TEE study included patients with an ischemic stroke or a TIA and no indication for OAC after routine work-up (including TTE, carotid ultrasound, ECG, and blood test) [16]. Besides an increased detection of aortic plaques and interatrial septum abnormalities using TEE, cardiac thrombi, almost exclusively located in the LA appendage (LAA), were found in $17 \%$ of the 231 patients compared to $1 \%$ of the patients who were examined with TTE only. However, no prolonged rhythm monitoring was performed and the incidence of newly detected AF was not reported. Considering that the detection of LAA thrombi in individuals with sinus rhythm and normal TTE is a rare finding $[17,18]$, it seems likely that there is a high rate of so far undetected $\mathrm{AF}$ in individuals with LAA thrombus. In a small retrospective singlecenter study, additional findings using TEE were again mainly related to interatrial septum abnormalities [19]. A retrospective analysis of the prospective FindAF RANDOMISED trialincluding ischemic stroke patients aged 60 years and olderrevealed that TEE findings led to a change in therapy in 14 out of 89 selected patients, whereas TTE findings led to a change in therapy in 1 out of 90 selected patients [20]. However, only a minority of patients received both TTE and TEE and the decision for TTE or TEE was not based on predefined criteria, limiting the direct comparison of both examinations. Furthermore, a significant proportion of the therapy changes based on TEE findings is debatable (mainly OAC in case of a newly diagnosed PFO). In a prospective multi-center observational study including 603 TIA patients, echocardiography (mainly TTE) revealed a potential source of cardioembolism in $10 \%$, with a higher yield in patients with known coronary artery disease (CAD) or in the presence of acute infarction on brain MRI. However, changes in medical therapy based on echocardiography were rare, which led the authors to conclude that the decision to perform echocardiography in TIA patients should be individualized [21].

Since stroke etiology remains unexplained in a relevant proportion of individuals after standard work-up including echocardiography, the incremental value of cardiac MRI and $\mathrm{CT}$ has been investigated [22]. In a prospective single-center study, 103 patients with cryptogenic stroke according to routine work-up including TEE and in most cases TTE were assigned to receive an additional MRI examination of the heart and the aorta $[7 \bullet \cdot]$. Although stroke classification based on findings from both imaging modalities was consistent in the vast majority of cases (86\%), cardiac MRI identified a potential source of embolism in additional $6.1 \%$, including four patients with regional wall motion abnormalities izn $\geq 3$ segments and one patient with aortic plaques $\geq 4 \mathrm{~mm}$. However, MRI missed echocardiography-detected sources of embolism in seven patients. In five of these seven cases, 
MRI had to be terminated prematurely due to intolerance by the patients or the need for an emergency examination in a different patient. The remaining two had a PFO combined with an ASA. In an earlier prospective single-center study, the additional benefit of cardiac MRI over routine work-up including TTE, but not TEE, was evaluated in 85 ischemic stroke patients [8]. Cardiac MRI identified a potential source of embolism in $6(26 \%)$ of the 23 patients who had been classified as a cryptogenic stroke after routine work-up. Three stroke patients had an evident embolic source (two LV thrombi and one complex aortic thrombus), whereas the other three were interatrial septum abnormalities (two ASAs, one ASA + PFO). The authors did not report on any pathological finding detected on TTE.

To date, the largest prospective single-center study comparing the combined CT examination of the heart, aorta and brain-supplying arteries with TTE and TEE enrolled 140 patients with the suspicion of cardioembolic stroke or TIA mainly based on brain imaging findings [9•]. Patients with AF on the admission ECG were excluded. Electrocardiogram-gated CT examinations revealed prior myocardial infarction (MI) more accurately than echocardiography and also detected an LV-thrombus in one additional patient, whereas three small thrombi in the LAA were missed by cardiac CT. The authors concluded that cardiac CT might offer complementary information for stroke classification. Another prospective singlecenter study compared cardiac CT with TTE and TEE in 46 unselected ischemic stroke patients [23]. With TEE as reference, cardiac CT had a sensitivity of $72 \%$ for the identification of potential cardiac source of embolism, with one LVthrombus only detected by cardiac CT. In an earlier singlecenter prospective study including 137 patients with suspicion for a cardioembolic stroke and a high cardiovascular risk profile, cardiac CT yielded similar results compared to TEE regarding high-risk sources of embolism [24]. However, many low-risk sources of embolism such as PFO/ASA were missed using cardiac CT only. In a small prospective single-center pilot study of 20 ischemic stroke patients, the feasibility of simultaneous cardiac CT examination along with the initial brain imaging was tested [25]. Cardiac CT revealed one LVthrombus and one LAA-thrombus, both validated using TEE the next day. Furthermore, one patient was diagnosed with a Stanford type A aortic dissection.

The advantages, disadvantages, and a comparison of the diagnostic value of all four cardiac imaging modalities are summarized in Table 1.

\section{Cardiac Imaging for Sources of Stroke}

\section{(Ischemic) Cardiomyopathy and Left Ventricular Thrombus}

Coronary artery disease is a common finding in patients with ischemic stroke. Coronary CT studies revealed obstructive $\mathrm{CAD}$ in up to $25 \%$ of symptom-free ischemic stroke patients

Table 1 Advantages, disadvantages, and diagnostic value of cardiac imaging methods (modified according to [10])

\begin{tabular}{|c|c|c|c|c|}
\hline & TTE & TEE & Cardiac MRI & Cardiac CT \\
\hline Advantages & $\begin{array}{l}\text { - Readily available } \\
\text { - Cheap } \\
\text { - Non-invasive }\end{array}$ & $\begin{array}{l}\text { - Excellent spatial and temporal } \\
\text { resolution }\end{array}$ & $\begin{array}{l}\text { - Good spatial resolution } \\
\text { - Excellent tissue } \\
\text { characterization }\end{array}$ & $\begin{array}{l}\text { - Excellent spatial resolution } \\
\text { - Fast acquisition }\end{array}$ \\
\hline Disadvantages & $\begin{array}{l}\text { - Operator dependent } \\
\text { - Limited by patient } \\
\text { characteristics } \\
\text { (e.g., obesity, lung disease) }\end{array}$ & $\begin{array}{l}\text { - Operator dependent } \\
\text { - Semi-invasive } \\
\text { - Usually requires sedation }\end{array}$ & $\begin{array}{l}\text { - Gadolinium exposure } \\
\text { - Most expensive } \\
\text { - Requires ability to hold } \\
\text { breath } \\
\text { - May require sedation } \\
\text { - Limited by patient } \\
\text { characteristics } \\
\text { (e.g., pacemaker) }\end{array}$ & $\begin{array}{l}\text { - Radiation } \\
\text { - Iodinated contrast agent } \\
\text { exposure } \\
\text { - Expensive }\end{array}$ \\
\hline Cardiomyopathy & ++ & + & $+++^{*}$ & - \\
\hline LV-thrombus & ++ & + & $+++*$ & ++ \\
\hline PFO & ++ & $+++*$ & - & + \\
\hline Valvular disease & ++ & $+++*$ & - & $++(+++)^{*}, \#$ \\
\hline Cardiac tumors & + & ++ & $+++^{*}$ & ++ \\
\hline LA/LAA & + & $+++*$ & ++ & ++ \\
\hline Aortic atheroma & - & ++ & ++ & $+++*$ \\
\hline
\end{tabular}

$C T$ computed tomography, $L A$ left atrium, $L A A$ left atrial appendage, $L V$ left ventricle, $M R I$ magnetic resonance imaging, $P F O$, patent foramen ovale, TEE transesophageal echocardiography, TTE transthoracic echocardiography

*Diagnostic gold standard

\# Offers supplemental information to TEE with regard to paravalvular extent of the disease and in patients with prosthetic valves 
without previously known CAD [26]. However, screening for occult CAD in stroke patients remains a matter of debate and current guidelines do not provide clear recommendations [12, 27]. Further diagnostic approaches in the acute phase after stroke might be guided by high-sensitivity assayed troponin concentrations, routinely used in the diagnosis of acute MI, which have been shown to be elevated frequently in ischemic stroke patients [28]. However, in a recent prospective twocenter study, only 7 of 29 ischemic stroke patients with elevated troponin concentrations who were referred to coronary angiography were diagnosed with a coronary culprit lesion, whereas 14 patients had no obstructive CAD at all [29]. Results from a small sub-study of nine patients suggest that cardiac MRI might be helpful to select stroke patients in need for an urgent coronary angiography, since it enables the detection of late gadolinium enhancement - consistent with prior $\mathrm{MI}$ - and subtle wall motion abnormalities not detected on TTE [30]. In a recent study, late gadolinium enhancement was detected in $15 \%$ of stroke patients without known CAD indicating the need for further cardiac diagnostic work-up (e.g., non-invasive myocardial stress tests) [7••]. Signs of MI in stroke patients undetected on TTE have also been demonstrated using cardiac CT [9•].

Regional wall motion abnormalities due to prior MI are the most common reason for the formation of LV-thrombi, although the incidence has significantly declined due to improved reperfusion strategies. However, LV-thrombi may still occur in up to $8 \%$ of patients after ST-elevation MI [31, 32]. According to a meta-analysis, LV-thrombi are associated with an increased risk for ischemic stroke that can be reduced by taking vitamin $\mathrm{K}$ antagonist OAC [33]. Cardiac MRI possesses higher sensitivity and specificity compared to TTE/TEE, rendering it the gold standard for the detection of LV-thrombi $[34,35]$. Since many LVthrombi are located in apical region of the LV, TTE is most frequently used for the detection of LV-thrombi and may serve as an initial screening test (Fig. 1a) [31,34]. The diagnostic yield of TTE can be improved by applying a contrast agent [35]. However, if suspicion for a LV-thrombus is high despite negative findings on TTE, a cardiac MRI should be performed [36•]. In a recent prospective single-center study including 60 ischemic stroke patients with an LV ejection fraction $<50 \%$ or a previous MI, cardiac MRI revealed LV-thrombi in twelve patients compared to one patient using TTE [36॰]. The detection of an LVthrombus was associated with a reduced LV ejection fraction compared to individuals without LV-thrombus. If cardiac MRI is not easily available, a CT might be considered as an alternative [9, 23].

Apart from LV-thrombi, other cardiomyopathies such as dilated or the rare LV non-compaction cardiomyopathy have also been linked to ischemic stroke [37-39]. While both diseases lead to a significant reduction of the LV ejection fraction, dilated cardiomyopathy is characterized by dilatation of the LV, whereas multiple prominent ventricular trabeculations with intertrabecular spaces can be found in non-compaction cardiomyopathy [37, 38]. Initial screening can be performed by TTE, preferably using contrast agent in case of suspicion for non-compaction in order to unmask the deep intertrabecular recesses (Fig. 1c) [3, 38]. Once more, cardiac MRI can secure the diagnosis and exclude LV thrombi.

\section{Patent Foramen Ovale}

While a PFO can be found in about $25 \%$ of the general population, its prevalence in young patients with cryptogenic stroke is reported to be up to $54 \%[40,41]$. It represents a potential mechanism for paradoxical embolism via a right-to-left shunt and is associated with an increased risk of stroke recurrence in the presence of an ASA [42, 43]. In 2017 and 2018, three randomized open-label trials were able to demonstrate a significant reduction of stroke recurrence rate by interventional PFO-closure compared to antiplatelets in patients with cryptogenic stroke aged 18-60 years $[44,45]$. Based on the currently available data, an interventional PFO-closure should be considered in selected patients with cryptogenic stroke, aged $\leq 60$ years with moderate to high atrial shunt volume after prior rigorous work-up including at least $72 \mathrm{~h}$ of rhythm monitoring.

A first screening for a PFO can be conducted using TTE with an intravenous injection of an agitated air-saline solution. A bubble transition from the right to the left atrium indicates an interatrial septum abnormality ("positive bubble test"). This procedure should be repeated while the patient performs a Valsalva maneuver, which has been shown to significantly improve PFO detection [46]. Large right-to-left shunts can usually be detected using TTE, while smaller shunts are frequently missed [47]. Transcranial Doppler examination after intravenous injection of agitated air-saline solution, gelatinbased solutions or Echovist ${ }^{\circledR}$ (Schering, Berlin, Germany) is a reliable alternative for initial screening for atrial right-to-left shunting in stroke patients. According to a meta-analysis of prospective studies with TEE as the reference, the weighted mean sensitivity and specificity of transcranial Doppler examination was $97 \%$ and 93\%, respectively [48]. In order to establish the exact anatomy and the precise shunt volume, a TEE examination including the bubble-test is necessary and is considered the gold standard for PFO diagnosis (Fig. 1e) [47]. However, there are case reports indicating bubble transition to the left atrium due to a pulmonary arteriovenous malformation in the absence of an atrial shunt [49].

Cardiac CT showed inferior results compared to TEE with regard to the detection of interatrial septum abnormalities [23, $24,50]$. In a retrospective single-center study including 152 stroke patients, a shunt was found in 19 out of 26 patients with TEE-detected PFO with two false positive results, resulting in a sensitivity and specificity of $73 \%$ and $98 \%$, respectively [50]. Nevertheless, cardiac CT might be an alternative in 
patients with contraindications for TEE, whereas cardiac MRI is not well suited for the diagnosis of a PFO [7, 51, 52].

\section{Valvular Disease}

Septic cerebral embolism occurs in up to $64 \%$ of patients with left-sided infective endocarditis with many episodes being silent and only detectable on cranial MRI [53]. European guidelines recommend TTE for initial screening in case of suspected infective endocarditis [54]. However, TEE is superior to TTE in diagnosing infective endocarditis, in particular in case of small vegetations, poor image quality or prosthetic heart valves (Fig. 1f) [55]. If clinical suspicion persists despite a negative TTE, a TEE examination should be performed and repeated if considered necessary [54]. Patients with a positive TTE should always undergo TEE for further assessment [54]. Echocardiography findings can aid risk stratification and guide therapeutic management based on vegetation size and degree of valvular destruction/ insufficiency [54]. Cardiac CT is a valuable alternative to TEE, in particular in patients with prosthetic valve infective endocarditis, in whom acoustic shadowing might impair visualization of the valves $[56,57]$. While small vegetations and leaflet perforations may be missed, CT is often superior to TEE for the assessment of the perivalvular extent of the disease $[56,57]$. The combination of positron emission tomography with CT can be helpful in case of inconclusive results [54].

Another potential source of cardioembolic stroke in patients with prosthetic valves is thrombus formation, often caused by inadequate anticoagulation [58]. Valve thrombosis is more common in mitral valve replacement than in aortic valve replacement and in mechanical prostheses compared to bioprostheses [59, 60]. Possible dysfunction of the valves might be revealed on TTE, but TEE should be performed for validation of the diagnosis [61]. In case of inconclusive results after TEE, cardiac CT can be performed for further clarification [61].

\section{Cardiac Tumors}

Cardiac tumors are rare sources of cardioembolism. The most common primary cardiac tumors in adults are myxomas, usually found in the LA, and the valve-associated papillary fibroelastomas (Fig. 1d) [3, 62, 63]. Both are benign and often first diagnosed after cardioembolic stroke [64, 65]. Initial screening can be achieved by echocardiography with TEE providing higher sensitivity and spatial resolution [66]. Cardiac CT and in particular MRI can be performed additionally to obtain information on the exact extent of the tumor, its vascularization and tissue characterization and to facilitate differential diagnosis [63].

\section{Left Atrial (Appendage) Thrombus}

The LA and, in particular, the LAA are the typical location for thrombus formation in patients with AF (Fig. 1b) [67]. TEE is considered the gold standard for LA/LAA thrombus evaluation [16]. Nevertheless, cardiac CT might be a valuable alternative as it is non-invasive and offers a superior visualization of the LAA anatomy compared to TEE [68]. In a metaanalysis of 19 studies, the mean sensitivity and specificity of cardiac CT was $96 \%$ and $92 \%$ compared to TEE, respectively [69]. Focusing on seven mostly prospective, single-center studies in which delayed imaging $\mathrm{CT}$ was performed further increased sensitivity (100\%) and specificity (99\%). Cardiac MRI has also been shown to be a reliable alternative for the evaluation of the LAA [70]. In a retrospective analysis of 261 registry patients undergoing pulmonary vein isolation, delayed enhancement cardiac MRI detected all nine thrombi found on TEE [71]. In line with this, an earlier prospective single-center study including 50 patients with prior cardioembolic stroke and persistent non-valvular AF revealed that cardiac MRI detected all TEE-detected thrombi, but three patients had false positive MRI findings due to artifacts [72]. Since the pathophysiological relationship between the presence of LA/LAA thrombi and cardioembolic stroke appears obvious, imaging of the LA/LAA in patients with stroke (of unknown etiology) seems to be a reasonable approach. However, LA/LAA thrombi are rarely found in patients with continuous sinus rhythm and without specific structural cardiac pathologies $[17,18]$.

\section{Cardiac Imaging for Atrial Cardiomyopathy and Prediction of Poststroke Atrial Fibrillation}

Of note, the prevalence of cryptogenic stroke according to TOAST criteria is about 25-30\%, including patients with (in) complete diagnostic evaluation and competing stroke etiologies [2, 4, 22]. Since the diagnostic work-up for cryptogenic stroke was not established, the term "embolic stroke of undetermined source (ESUS)" has been introduced [73]. ESUS is defined as an imaging-confirmed non-lacunar stroke without extra- or intracranial atherosclerosis causing $\geq 50 \%$ stenosis in an artery supplying the area of recent brain ischemia, apparent major-risk cardioembolic source determined by echocardiography (using TTE or TEE), no episode of AF $\geq$ 6 min within $24 \mathrm{~h}$ of ECG monitoring, and no other specific cause of stroke [73]. Results from long-term ECG monitoring led to the assumption, that a significant proportion of cryptogenic stroke as well as ESUS might have been caused by subclinical AF as well [4, 11]. As a clear biological gradient between AF burden and stroke risk has to be questioned, the concept of atrial cardiomyopathy as an alternative source of cardioembolism was proposed [74-76]. In a consensus paper from 2016, atrial cardiomyopathy was defined as "any complex of structural, architectural, contractile or electrophysiological changes affecting the atria with the potential to produce clinically-relevant manifestations," including AF and 
stroke [77]. Underlying structural changes of the atria might be visualized using TTE/TEE, CT, or MRI $[77,78]$. It remains to be established whether atrial cardiomyopathy and its proposed biomarkers alone are sufficient for thrombus formation with subsequent stroke or merely serve as surrogate parameters for subclinical AF [79].

Cardiac imaging provides valuable information for further management of patients with unknown stroke etiology. Guidance on who to screen for AF is urgently needed considering that recent studies in ESUS patients failed to demonstrate a beneficial effect of empirical anticoagulation [80, 81]. Furthermore, despite documented overall cost-effectiveness, prolonged ECG monitoring is often restricted due to higher cost at the individual level and limited man power as well as technical resources [11, 82]. Beside patients' characteristics such as older age, laboratory, as well as ECG findings, echocardiography might aid patient selection for prolonged ECG monitoring [11, 13, 83, 84]. Echocardiography, in particular TTE, seems to be a reasonable method to guide AF screening considering its comparatively low costs and wide availability [85]. Left atrial volume, preferably indexed on body surface area (LA volume index), has been demonstrated to be predictive for the detection of incident AF [85-87]. Quantification of LA volume can be further optimized using threedimensional TTE [88]. Furthermore, parameters of LV diastolic dysfunction and atrial function might serve as indicators for an increased risk of incident $\mathrm{AF}[89,90]$. In a recent retrospective single-center study on 531 cryptogenic stroke patients, low atrial strain as well as global longitudinal strain of the LV showed incremental value for AF risk prediction over LA volume, LV ejection fraction and $\mathrm{E} / \mathrm{e}^{\prime}$ ratio [91•]. This is in line with results from another retrospective single-center study on 616 cryptogenic stroke patients [92]. In a recent small prospective single-center study with 56 cryptogenic stroke patients who had a cardiac monitor implanted for AF monitoring, low left atrial strain predicted incident AF independent of classical parameters of diastolic dysfunction, global longitudinal LV strain and cardiovascular risk factors [93]. Low atrial strain has further been shown to correspond with atrial fibrosis detected on cardiac MRI and might therefore be a good surrogate parameter for atrial remodeling [94, 95]. However, these new parameters are based on speckle tracking imaging and might not yet be routinely assessed.

The time interval from the beginning of the $\mathrm{P}$ wave on the surface ECG to the peak of the $\mathrm{A}^{\prime}$ wave obtained by tissue Doppler imaging (TDI), the so-called PA-TDI, is an easily derivable echocardiographic parameter that reflects total atrial conduction time. It is inversely correlated with LA-strain and is associated with atrial fibrosis as well [96, 97]. An increased PA-TDI has been shown to be predictive of incident AF in different patient cohorts, including patients with cryptogenic stroke [98-100]. While the detection of spontaneous echo contrast or even thrombi in the LAA is associated with increased risk for mortality and LAA morphology has been linked to thromboembolic risk, it is uncertain whether they are relevant predictors of AF detection after a stroke [101-103]. Valvular abnormalities (particularly advanced atrioventricular valve diseases) are also associated with $\mathrm{AF}$ in stroke patients [83].

Table 2 Proposed diagnostic approach to cardiac imaging in patients with ischemic stroke

Medical history, patient characteristics, laboratory, ultrasound, ECG and brain imaging findings

\begin{tabular}{|c|c|c|c|}
\hline $\begin{array}{l}\text { Presumed stroke } \\
\text { etiology }\end{array}$ & $\mathrm{AF}$ & $\begin{array}{l}\text { Determined etiology } \\
\text { (exceptcardioembolism) at } \\
\text { cardiovascular disease risk }\end{array}$ & $\begin{array}{l}\text { Suspected (cardio-) } \\
\text { embolism/unknown }\end{array}$ \\
\hline $\begin{array}{l}\text { Recommended } \\
\text { imaging method }\end{array}$ & TTE & TTE & TTE and TEE \\
\hline $\begin{array}{l}\text { Alternative } \\
\text { imaging method }\end{array}$ & $\begin{array}{l}\text { TEE (if presence of left atrial } \\
\text { thrombus impacts } \\
\text { on timing of OAC) }\end{array}$ & - & $\begin{array}{l}\text { Cardiac CT/MRI in case of } \\
\text { contraindications for } \\
\text { TEE/inconclusive results }\end{array}$ \\
\hline Timing of imaging & During in-hospital stay & $\begin{array}{l}\text { During in-hospital stay } \\
\text { or after discharge }\end{array}$ & During in-hospital stay \\
\hline Imaging objectives & $\begin{array}{l}\text { - Screening for concomitant } \\
\text { structural abnormalities/(coronary) } \\
\text { heart disease } \\
\text { - Stroke risk assessment } \\
\text { - Guiding timing of starting / } \\
\text { continuing OAC }\end{array}$ & $\begin{array}{l}\text { - Screening for competing } \\
\text { stroke mechanisms } \\
\text { - Screening for concomitant } \\
\text { structural } \\
\text { abnormalities/(coronary) } \\
\text { heart disease }\end{array}$ & $\begin{array}{l}\text { - Screening for potential source } \\
\text { of cardioembolism } \\
\text { - Screening for concomitant } \\
\text { structural abnormalities/(coronary) } \\
\text { heart disease } \\
\text { - Prediction of incident AF during } \\
\text { long-term ECG monitoring }\end{array}$ \\
\hline
\end{tabular}

$A F$ atrial fibrillation, $C T$ computed tomography, $E C G$ electrocardiogram, TEE transoesophageal echocardiography, TTE transthoracic echocardiography, MRI magnetic resonance imaging, OAC oral anticoagulation 


\section{Guideline Recommendations}

The European Stroke Organization guideline issued in 2008 recommends echocardiography in selected ischemic stroke or TIA patients, e.g., "in suspected cardiac source of embolism," "evidence of cardiac disease on history, examination, or ECG" or if "no other identifiable causes of stroke" is identified (class III, level B recommendation) [27]. However, no recommendation is given as to the choice of TTE or TEE. In a recent consensus statement from the European Stroke OrganizationKarolinska Stroke Update Conference, TTE was considered the primary choice for cardiac imaging (grade A), while TEE and bubble test-transcranial Doppler were recommended in patients with ESUS for detection of a PFO (grade A) as well as TEE over TTE to detect aortic atheroma (grade C) [84]. The recently updated American Heart Association guideline on acute stroke management considers echocardiography reasonable in selected ischemic stroke patients to guide secondary stroke prevention (class IIa recommendation, expert opinion) and to determine whether eligibility criteria for a PFO closure are met in patients with ESUS (class IIa recommendation, evidence from randomized trials) [104]. The American Society of Echocardiography guidelines were published in 2016 and recommend routine use of TTE as a screening tool for potential cardiac sources of embolism in case of an ischemic stroke or a TIA, while TEE might be considered as an initial or supplemental test in specific cases, e.g., suspicion for endocarditis [105]. Cardiac CT and MRI should be reserved to selected patients with high suspicion for cardioembolism and inconclusive results after echocardiography [105]. Due to its semi-invasive nature, TEE is not recommended if potential results will not change therapeutic decisions [105]. The European Association of Echocardiography recommendations, published in 2010, consider TTE the primary choice for cardiac imaging after ischemic stroke in most individuals. However, TEE is additionally recommended in specific cases despite negative finding on TTE, e.g., in case of suspicion for endocarditis, a PFO or for the evaluation of prosthetic valves [3]. The Canadian Stroke Best Practice Recommendations for Acute Stroke Management state that echocardiography should be considered in patients with suspected embolic stroke or TIA and normal neurovascular imaging without a contraindication for OAC [106].

\section{Conclusions}

Echocardiography constitutes the primary choice for cardiac imaging after acute ischemic stroke with TTE and TEE providing complementary information (Table 2 ). TTE accurately visualizes cardiac function and should be the first choice in most patients considering its non-invasive character and wide availability. TTE findings might also help to select patients undergoing prolonged rhythm monitoring for a first episode of AF. TEE can provide additional information, e.g., on left atrial pathologies, and should in particular be used in patients with suspected cardioembolic stroke. Cardiac CT or MRI are a valuable alternative in specific situations but cannot be recommended as primary imaging methods at the moment. Further imaging studies in patients with acute ischemic stroke or TIA are needed to better guide clinical practice. Of note, the prognostic benefit of cardiac imaging guided therapy changes following ischemic stroke or TIA has yet to be demonstrated.

Funding Information Open Access funding provided by Projekt DEAL.

\section{Compliance with ethical standards}

Conflict of interest RBS reports speaking fees from Bristol-Myers Squibb/Pfizer. RBS further received funding from the European Union's Horizon 2020 research and innovation programme under the (grant agreement No. 847770, AFFECT-EU), the European Research Council (ERC) under the European Union's Horizon 2020 research and innovation programme (grant agreement No. 648131), and ERACoSysMed3 (031L0239) and German Center for Cardiovascular Research (DZHK e.V.) (81Z1710103). KGH reports consulting fees/lecture honoraria from Bayer Healthcare, Biotronik, Boehringer Ingelheim, Bristol-Myers Squibb, Daiichi Sankyo, Edwards Lifesciences, Medronic, Pfizer, Sanofi, W.L. Gore and Associates, and study grants from Bayer HealthCare and Sanofi. SC reports no conflict of interest.

Human and Animal Rights This article does not contain any studies with human or animal subjects performed by any of the authors.

Open Access This article is licensed under a Creative Commons Attribution 4.0 International License, which permits use, sharing, adaptation, distribution and reproduction in any medium or format, as long as you give appropriate credit to the original author(s) and the source, provide a link to the Creative Commons licence, and indicate if changes were made. The images or other third party material in this article are included in the article's Creative Commons licence, unless indicated otherwise in a credit line to the material. If material is not included in the article's Creative Commons licence and your intended use is not permitted by statutory regulation or exceeds the permitted use, you will need to obtain permission directly from the copyright holder. To view a copy of this licence, visit http://creativecommons.org/licenses/by/4.0/.

\section{References}

Papers of particular interest, published recently, have been highlighted as:

- Of importance

•• Of major importance

1. Adams HP, Jr., Bendixen BH, Kappelle LJ, Biller J, Love BB, Gordon DL, Marsh 3rd EE Classification of subtype of acute ischemic stroke. Definitions for use in a multicenter clinical trial. TOAST. Trial of Org 10172 in Acute Stroke Treatment. Stroke. 1993;24(1):35-41. 
2. Kolominsky-Rabas PL, Weber M, Gefeller O, Neundoerfer B, Heuschmann PU. Epidemiology of ischemic stroke subtypes according to TOAST criteria: incidence, recurrence, and long-term survival in ischemic stroke subtypes: a population-based study. Stroke. 2001;32(12):2735-40.

3. Pepi M, Evangelista A, Nihoyannopoulos P, Flachskampf FA, Athanassopoulos G, Colonna P, et al. Recommendations for echocardiography use in the diagnosis and management of cardiac sources of embolism: European Association of Echocardiography (EAE) (a registered branch of the ESC). Eur J Echocardiogr. 2010;11(6):461-76. https://doi.org/10.1093/ ejechocard/jeq045.

4. Haeusler KG, Tutuncu S, Schnabel RB. Detection of atrial fibrillation in cryptogenic stroke. Curr Neurol Neurosci Rep. 2018;18(10):66. https://doi.org/10.1007/s11910-018-0871-1.

5. Ng VT, Bayoumi AM, Fang J, Burton KR, Stamplecoski M, Edwards JD, et al. Temporal trends in the use of investigations after stroke or transient ischemic attack. Med Care. 2016;54(5): 430-4. https://doi.org/10.1097/mlr.0000000000000499.

6. Giruparajah M, Bosch J, Vanassche T, Mattina K, Connolly SJ, Pater C, et al. Global survey of the diagnostic evaluation and management of cryptogenic ischemic stroke. Int J Stroke. 2015;10(7):1031-6. https://doi.org/10.1111/ijs.12509.

7.• Haeusler KG, Wollboldt C, Bentheim LZ, Herm J, Jager S, Kunze $\mathrm{C}$, et al. Feasibility and diagnostic value of cardiovascular magnetic resonance imaging after acute ischemic stroke of undetermined origin. Stroke. 2017;48(5):1241-7. https://doi.org/10.1161/ STROKEAHA.116.016227 Recent study investigating the additional benefit of cardiac MRI over routine work-up including TTE/TEE in patients with cryptogenic stroke. The authors were able to demonstrate the feasibility of cardiac MRI in acute stroke patients and concluded that cardiac MRI might offer complementary information to echocardiography.

8. Baher A, Mowla A, Kodali S, Polsani VR, Nabi F, Nagueh SF, et al. Cardiac MRI improves identification of etiology of acute ischemic stroke. Cerebrovasc Dis. 2014;37(4):277-84. https:// doi.org/10.1159/000360073.

9. Sipola P, Hedman M, Onatsu J, Turpeinen A, Halinen M, Jakala P et al. Computed tomography and echocardiography together reveal more high-risk findings than echocardiography alone in the diagnostics of stroke etiology. Cerebrovasc Dis. 2013;35(6):52130. doi:https://doi.org/10.1159/000350734. The authors evaluated the value of ECG-gated cardiac CT compared with TTE/TEE and found that CT allows additional detection of previous (silent) myocardial infarction, whereas small thrombi in the LAA were missed.

10. Camen S, Haeusler KG, Schnabel RB. Cardiac imaging after ischemic stroke : echocardiography, CT, or MRI? Herz. 2019;44(4): 296-303. https://doi.org/10.1007/s00059-019-4803-x.

11. Schnabel RB, Haeusler KG, Healey JS, Freedman B, Boriani G, Brachmann J, et al. Searching for atrial fibrillation poststroke: a white paper of the AF-SCREEN International Collaboration. Circulation. 2019;140(22):1834-50. https://doi.org/10.1161/ circulationaha.119.040267.

12. Adams RJ, Chimowitz MI, Alpert JS, Awad IA, Cerqueria MD, Fayad P, et al. Coronary risk evaluation in patients with transient ischemic attack and ischemic stroke: a scientific statement for healthcare professionals from the Stroke Council and the Council on Clinical Cardiology of the American Heart Association/American Stroke Association. Circulation. 2003;108(10):1278-90. https://doi.org/10.1161/01.cir. 0000090444.87006.cf.

13. Haeusler KG, Groschel K, Kohrmann M, Anker SD, Brachmann $\mathrm{J}$, Bohm M, et al. Expert opinion paper on atrial fibrillation detection after ischemic stroke. Clin Res Cardiol. 2018;107(10): 871-80. https://doi.org/10.1007/s00392-018-1256-9.

14. Heidrich J, Heuschmann PU, Kolominsky-Rabas P, Rudd AG, Wolfe CD. Variations in the use of diagnostic procedures after acute stroke in Europe: results from the BIOMED II study of stroke care. Eur J Neurol. 2007;14(3):255-61. https://doi.org/10. 1111/j.1468-1331.2006.01573.x.

15. Harloff A, Handke M, Reinhard M, Geibel A, Hetzel A. Therapeutic strategies after examination by transesophageal echocardiography in 503 patients with ischemic stroke. Stroke. 2006;37(3):859-64. https://doi.org/10.1161/01.STR. 0000202592.87021.b7.

16. de Bruijn SF, Agema WR, Lammers GJ, van der Wall EE, Wolterbeek R, Holman ER, et al. Transesophageal echocardiography is superior to transthoracic echocardiography in management of patients of any age with transient ischemic attack or stroke. Stroke. 2006;37(10):2531-4. https://doi.org/10.1161/01. str.0000241064.46659.69.

17. Agmon Y, Khandheria BK, Gentile F, Seward JB. Clinical and echocardiographic characteristics of patients with left atrial thrombus and sinus rhythm: experience in 20643 consecutive transesophageal echocardiographic examinations. Circulation. 2002;105(1):27-31.

18. Leung DY, Black IW, Cranney GB, Walsh WF, Grimm RA, Stewart WJ, et al. Selection of patients for transesophageal echocardiography after stroke and systemic embolic events. Role of transthoracic echocardiography. Stroke. 1995;26(10):1820-4.

19. Zhang L, Harrison JK, Goldstein LB. Echocardiography for the detection of cardiac sources of embolism in patients with stroke or transient ischemic attack. J Stroke Cerebrovasc Dis. 2012;21(7): 577-82. https://doi.org/10.1016/j.jstrokecerebrovasdis.2011.01. 005.

20. Wasser K, Weber-Kruger M, Jurries F, Liman J, Hamann GF, Kermer $\mathrm{P}$, et al. The cardiac diagnostic work-up in stroke patients-a subanalysis of the Find-AFRANDOMISED trial. PLoS One. 2019;14(5):e0216530. https://doi.org/10.1371/ journal.pone.0216530.

21. Wilson CA, Tai W, Desai JA, Mulvihill I, Olivot JM, Murphy S, et al. Diagnostic yield of echocardiography in transient ischemic attack. J Stroke Cerebrovasc Dis. 2016;25(5):1135-40. https://doi. org/10.1016/j.jstrokecerebrovasdis.2016.01.011.

22. Hart RG, Catanese L, Perera KS, Ntaios G, Connolly SJ. Embolic stroke of undetermined source: a systematic review and clinical update. Stroke. 2017;48(4):867-72. https://doi.org/10.1161/ strokeaha.116.016414.

23. Boussel L, Cakmak S, Wintermark M, Nighoghossian N, Loffroy $\mathrm{R}$, Coulon $\mathrm{P}$, et al. Ischemic stroke: etiologic work-up with multidetector CT of heart and extra- and intracranial arteries. Radiology. 2011;258(1):206-12. https://doi.org/10.1148/radiol. 10100804 .

24. Hur J, Kim YJ, Lee HJ, Ha JW, Heo JH, Choi EY, et al. Cardiac computed tomographic angiography for detection of cardiac sources of embolism in stroke patients. Stroke. 2009;40(6): 2073-8. https://doi.org/10.1161/strokeaha.108.537928.

25. Yeo LLL, Holmin S, Andersson T, Lundstrom E, Gopinathan A, Lim EL, et al. Nongated cardiac computed tomographic angiograms for detection of embolic sources in acute ischemic stroke. Stroke. 2017;48(5):1256-61. https://doi.org/10.1161/strokeaha. 117.016903 .

26. Amarenco P, Lavallee PC, Labreuche J, Ducrocq G, Juliard JM, Feldman L, et al. Prevalence of coronary atherosclerosis in patients with cerebral infarction. Stroke. 2011;42(1):22-9. https:// doi.org/10.1161/strokeaha.110.584086.

27. European Stroke Organisation C. Guidelines for management of ischaemic stroke and transient ischaemic attack 2008. 
Cerebrovasc Dis. 2008;25(5):457-507. https://doi.org/10.1159/ 000131083

28. Scheitz JF, Nolte CH, Laufs U, Endres M. Application and interpretation of high-sensitivity cardiac troponin assays in patients with acute ischemic stroke. Stroke. 2015;46(4):1132-40. https:// doi.org/10.1161/strokeaha.114.007858.

29. Mochmann HC, Scheitz JF, Petzold GC, Haeusler KG, Audebert HJ, Laufs U, et al. Coronary angiographic findings in acute ischemic stroke patients with elevated cardiac troponin: the Troponin Elevation in Acute Ischemic Stroke (TRELAS) study. Circulation. 2016;133(13):1264-71. https://doi.org/10.1161/circulationaha. 115.018547.

30. Haeusler KG, Jensen C, Scheitz JF, Krause T, Wollboldt C, Witzenbichler $\mathrm{B}$, et al. Cardiac magnetic resonance imaging in patients with acute ischemic stroke and elevated troponin: a TRoponin ELevation in Acute Ischemic Stroke (TRELAS) substudy. Cerebrovasc Dis Extra. 2019;9(1):19-24. https://doi.org/ $10.1159 / 000498864$

31. Weinsaft JW, Kim J, Medicherla CB, Ma CL, Codella NC, Kukar $\mathrm{N}$, et al. Echocardiographic algorithm for post-myocardial infarction LV thrombus: a gatekeeper for thrombus evaluation by delayed enhancement CMR. JACC Cardiovasc Imaging. 2016;9(5): 505-15. https://doi.org/10.1016/j.jcmg.2015.06.017.

32. Gianstefani S, Douiri A, Delithanasis I, Rogers T, Sen A, Kalra S, et al. Incidence and predictors of early left ventricular thrombus after ST-elevation myocardial infarction in the contemporary era of primary percutaneous coronary intervention. Am J Cardiol. 2014;113(7):1111-6. https://doi.org/10.1016/j.amjcard.2013.12. 015.

33. Vaitkus PT, Barnathan ES. Embolic potential, prevention and management of mural thrombus complicating anterior myocardial infarction: a meta-analysis. J Am Coll Cardiol. 1993;22(4):1004 9.

34. Srichai MB, Junor C, Rodriguez LL, Stillman AE, Grimm RA, Lieber ML, et al. Clinical, imaging, and pathological characteristics of left ventricular thrombus: a comparison of contrastenhanced magnetic resonance imaging, transthoracic echocardiography, and transesophageal echocardiography with surgical or pathological validation. Am Heart J. 2006;152(1):75-84. https:// doi.org/10.1016/j.ahj.2005.08.021

35. Weinsaft JW, Kim RJ, Ross M, Krauser D, Manoushagian S, LaBounty TM, et al. Contrast-enhanced anatomic imaging as compared to contrast-enhanced tissue characterization for detection of left ventricular thrombus. JACC Cardiovasc Imaging. 2009;2(8):969-79. https://doi.org/10.1016/j.jcmg.2009.03.017.

36. Takasugi J, Yamagami H, Noguchi T, Morita Y, Tanaka T, Okuno Y et al. Detection of left ventricular thrombus by cardiac magnetic resonance in embolic stroke of undetermined source. Stroke. 2017;48(9):2434-40. doi:https://doi.org/10.1161/ strokeaha.117.018263. In this study the authors were able to detect $L V$-thrombi in $20 \%$ of ischemic stroke patients with a prior MI or a $\mathbf{L V}$ ejection fraction $<\mathbf{5 0 \%}$ using cardiac MRI.

37. Oechslin EN, Attenhofer Jost CH, Rojas JR, Kaufmann PA, Jenni R. Long-term follow-up of 34 adults with isolated left ventricular noncompaction: a distinct cardiomyopathy with poor prognosis. J Am Coll Cardiol. 2000;36(2):493-500.

38. Captur G, Nihoyannopoulos P. Left ventricular non-compaction: genetic heterogeneity, diagnosis and clinical course. Int J Cardiol. 2010;140(2):145-53. https://doi.org/10.1016/j.ijcard.2009.07. 003.

39. Sirajuddin RA, Miller AB, Geraci SA. Anticoagulation in patients with dilated cardiomyopathy and sinus rhythm: a critical literature review. J Card Fail. 2002;8(1):48-53. https://doi.org/10.1054/jcaf. 2002.31907.

40. Lechat P, Mas JL, Lascault G, Loron P, Theard M, Klimczac M, et al. Prevalence of patent foramen ovale in patients with stroke. N
Engl J Med. 1988;318(18):1148-52. https://doi.org/10.1056/ nejm198805053181802.

41. Hagen PT, Scholz DG, Edwards WD. Incidence and size of patent foramen ovale during the first 10 decades of life: an autopsy study of 965 normal hearts. Mayo Clin Proc. 1984;59(1):17-20.

42. Handke M, Harloff A, Olschewski M, Hetzel A, Geibel A. Patent foramen ovale and cryptogenic stroke in older patients. N Engl J Med. 2007;357(22):2262-8. https://doi.org/10.1056/ NEJMoa071422.

43. Mas JL, Arquizan C, Lamy C, Zuber M, Cabanes L, Derumeaux $\mathrm{G}$, et al. Recurrent cerebrovascular events associated with patent foramen ovale, atrial septal aneurysm, or both. N Engl J Med. 2001;345(24):1740-6. https://doi.org/10.1056/NEJMoa011503.

44. Lee PH, Song JK, Kim JS, Heo R, Lee S, Kim DH, et al. Cryptogenic stroke and high-risk patent foramen ovale: the DEFENSE-PFO trial. J Am Coll Cardiol. 2018;71(20):2335-42. https://doi.org/10.1016/j.jacc.2018.02.046.

45. Ntaios G, Papavasileiou V, Sagris D, Makaritsis K, Vemmos K, Steiner T, et al. Closure of patent foramen ovale versus medical therapy in patients with cryptogenic stroke or transient ischemic attack: updated systematic review and meta-analysis. Stroke. 2018;49(2):412-8. https://doi.org/10.1161/strokeaha.117.020030.

46. Clarke NR, Timperley J, Kelion AD, Banning AP. Transthoracic echocardiography using second harmonic imaging with Valsalva manoeuvre for the detection of right to left shunts. Eur J Echocardiogr. 2004;5(3):176-81. https://doi.org/10.1016/s15252167(03)00076-3.

47. Maffe S, Dellavesa P, Zenone F, Paino AM, Paffoni P, Perucca A, et al. Transthoracic second harmonic two- and three-dimensional echocardiography for detection of patent foramen ovale. Eur $\mathrm{J}$ Echocardiogr. 2010;11(1):57-63. https://doi.org/10.1093/ ejechocard/jep165.

48. Mojadidi MK, Roberts SC, Winoker JS, Romero J, GoodmanMeza D, Gevorgyan R, et al. Accuracy of transcranial Doppler for the diagnosis of intracardiac right-to-left shunt: a bivariate meta-analysis of prospective studies. JACC Cardiovasc Imaging. 2014;7(3):236-50. https://doi.org/10.1016/j.jcmg.2013.12.011.

49. Bertram KL, Madan A, Frayne J. Isolated asymptomatic pulmonary arteriovenous malformation presenting with ischaemic stroke. J Clin Neurosci. 2016;29:189-91. https://doi.org/10. 1016/j.jocn.2016.01.006.

50. Kim YJ, Hur J, Shim CY, Lee HJ, Ha JW, Choe KO, et al. Patent foramen ovale: diagnosis with multidetector CT-comparison with transesophageal echocardiography. Radiology. 2009;250(1):617. https://doi.org/10.1148/radiol.2501080559.

51. Hamilton-Craig C, Sestito A, Natale L, Meduri A, Santangeli P, Infusino $\mathrm{F}$, et al. Contrast transoesophageal echocardiography remains superior to contrast-enhanced cardiac magnetic resonance imaging for the diagnosis of patent foramen ovale. Eur $\mathbf{J}$ Echocardiogr. 2011;12(3):222-7. https://doi.org/10.1093/ ejechocard/jeq177.

52. Nusser T, Hoher M, Merkle N, Grebe OC, Spiess J, Kestler HA, et al. Cardiac magnetic resonance imaging and transesophageal echocardiography in patients with transcatheter closure of patent foramen ovale. J Am Coll Cardiol. 2006;48(2):322-9. https://doi. org/10.1016/j.jacc.2006.03.036.

53. Duval X, Iung B, Klein I, Brochet E, Thabut G, Arnoult F, et al. Effect of early cerebral magnetic resonance imaging on clinical decisions in infective endocarditis: a prospective study. Ann Intern Med. 2010;152(8):497-504, w175. https://doi.org/10.7326/00034819-152-8-201004200-00006.

54. Habib G, Lancellotti P, Antunes MJ, Bongiorni MG, Casalta JP, Del Zotti F, et al. 2015 ESC guidelines for the management of infective endocarditis: the Task Force for the Management of Infective Endocarditis of the European Society of Cardiology (ESC). Endorsed by: European Association for Cardio-Thoracic 
Surgery (EACTS), the European Association of Nuclear Medicine (EANM). Eur Heart J. 2015;36(44):3075-128. https://doi.org/10. 1093/eurheartj/ehv319.

55. Bai AD, Steinberg M, Showler A, Burry L, Bhatia RS, Tomlinson GA et al. Diagnostic accuracy of transthoracic echocardiography for infective endocarditis findings using transesophageal echocardiography as the reference standard: a meta-analysis. J Am Soc Echocardiogr. 2017;30(7):639-46.e8. doi:https://doi.org/10.1016/ j.echo.2017.03.007.

56. Feuchtner GM, Stolzmann P, Dichtl W, Schertler T, Bonatti J, Scheffel H, et al. Multislice computed tomography in infective endocarditis: comparison with transesophageal echocardiography and intraoperative findings. J Am Coll Cardiol. 2009;53(5):43644. https://doi.org/10.1016/j.jacc.2008.01.077.

57. Habets J, Tanis W, Reitsma JB, van den Brink RB, Mali WP, Chamuleau SA, et al. Are novel non-invasive imaging techniques needed in patients with suspected prosthetic heart valve endocarditis? A systematic review and meta-analysis. Eur Radiol. 2015;25(7):2125-33. https://doi.org/10.1007/s00330-015-36057.

58. Durrleman N, Pellerin M, Bouchard D, Hebert Y, Cartier R, Perrault LP, et al. Prosthetic valve thrombosis: twenty-year experience at the Montreal Heart Institute. J Thorac Cardiovasc Surg. 2004;127(5):1388-92. https://doi.org/10.1016/j.jtcvs.2003.12. 013.

59. Puvimanasinghe JP, Steyerberg EW, Takkenberg JJ, Eijkemans MJ, van Herwerden LA, Bogers AJ, et al. Prognosis after aortic valve replacement with a bioprosthesis: predictions based on meta-analysis and microsimulation. Circulation. 2001;103(11): 1535-41.

60. Cannegieter SC, Rosendaal FR, Briet E. Thromboembolic and bleeding complications in patients with mechanical heart valve prostheses. Circulation. 1994;89(2):635-41.

61. Lim WY, Lloyd G, Bhattacharyya S. Mechanical and surgical bioprosthetic valve thrombosis. Heart. 2017;103(24):1934-41. https://doi.org/10.1136/heartjnl-2017-311856.

62. Klarich KW, Enriquez-Sarano M, Gura GM, Edwards WD, Tajik AJ, Seward JB. Papillary fibroelastoma: echocardiographic characteristics for diagnosis and pathologic correlation. J Am Coll Cardiol. 1997;30(3):784-90.

63. Hoey ET, Mankad K, Puppala S, Gopalan D, Sivananthan MU. MRI and CT appearances of cardiac tumours in adults. Clin Radiol. 2009;64(12):1214-30. https://doi.org/10.1016/j.crad. 2009.09.002.

64. Gowda RM, Khan IA, Nair CK, Mehta NJ, Vasavada BC, Sacchi TJ. Cardiac papillary fibroelastoma: a comprehensive analysis of 725 cases. Am Heart J. 2003;146(3):404-10. https://doi.org/10. 1016/s0002-8703(03)00249-7.

65. Pinede L, Duhaut P, Loire R. Clinical presentation of left atrial cardiac myxoma. A series of 112 consecutive cases. Medicine (Baltimore) 2001;80(3):159-172.

66. Engberding R, Daniel WG, Erbel R, Kasper W, Lestuzzi C, Curtius JM, et al. Diagnosis of heart tumours by transoesophageal echocardiography: a multicentre study in 154 patients. European Cooperative Study Group. Eur Heart J. 1993;14(9):1223-8.

67. Blackshear JL, Odell JA. Appendage obliteration to reduce stroke in cardiac surgical patients with atrial fibrillation. Ann Thorac Surg. 1996;61(2):755-9. https://doi.org/10.1016/0003-4975(95) 00887-x.

68. Pathan F, Hecht H, Narula J, Marwick TH. Roles of transesophageal echocardiography and cardiac computed tomography for evaluation of left atrial thrombus and associated pathology: a review and critical analysis. JACC Cardiovasc Imaging. 2018;11(4): 616-27. https://doi.org/10.1016/j.jcmg.2017.12.019.

69. Romero J, Husain SA, Kelesidis I, Sanz J, Medina HM, Garcia MJ. Detection of left atrial appendage thrombus by cardiac computed tomography in patients with atrial fibrillation: a metaanalysis. Circulation Cardiovascular imaging. 2013;6(2):185-94. https://doi.org/10.1161/circimaging.112.000153.

70. Vira T, Pechlivanoglou P, Connelly K, Wijeysundera HC, Roifman I. Cardiac computed tomography and magnetic resonance imaging vs. transoesophageal echocardiography for diagnosing left atrial appendage thrombi. Europace. 2018. doi:https:/ doi.org/10.1093/europace/euy142,.

71. Kitkungvan D, Nabi F, Ghosn MG, Dave AS, Quinones M, Zoghbi WA, et al. Detection of LA and LAA thrombus by CMR in patients referred for pulmonary vein isolation. JACC Cardiovasc Imaging. 2016;9(7):809-18. https://doi.org/10.1016/ j.jcmg.2015.11.029.

72. Ohyama H, Hosomi N, Takahashi T, Mizushige K, Osaka K, Kohno M, et al. Comparison of magnetic resonance imaging and transesophageal echocardiography in detection of thrombus in the left atrial appendage. Stroke. 2003;34(10):2436-9. https://doi.org/ 10.1161/01.str.0000090350.73614.0f.

73. Hart RG, Diener HC, Coutts SB, Easton JD, Granger CB, O'Donnell MJ, et al. Embolic strokes of undetermined source: the case for a new clinical construct. Lancet Neurol. 2014;13(4): 429-38. https://doi.org/10.1016/s1474-4422(13)70310-7.

74. Kamel H, Okin PM, Elkind MS, Iadecola C. Atrial fibrillation and mechanisms of stroke: time for a new model. Stroke. 2016;47(3): 895-900. https://doi.org/10.1161/STROKEAHA.115.012004.

75. Hirsh BJ, Copeland-Halperin RS, Halperin JL. Fibrotic atrial cardiomyopathy, atrial fibrillation, and thromboembolism: mechanistic links and clinical inferences. J Am Coll Cardiol. 2015;65(20): 2239-51. https://doi.org/10.1016/j.jacc.2015.03.557.

76. Brambatti M, Connolly SJ, Gold MR, Morillo CA, Capucci A, Muto $\mathrm{C}$, et al. Temporal relationship between subclinical atrial fibrillation and embolic events. Circulation. 2014;129(21):2094 9. https://doi.org/10.1161/CIRCULATIONAHA.113.007825.

77. Goette A, Kalman JM, Aguinaga L, Akar J, Cabrera JA, Chen SA, et al. EHRA/HRS/APHRS/SOLAECE expert consensus on atrial cardiomyopathies: definition, characterization, and clinical implication. Europace. 2016;18(10):1455-90. https://doi.org/10.1093/ europace/euw161.

78. Donal E, Lip GY, Galderisi M, Goette A, Shah D, Marwan M, et al. EACVI/EHRA Expert Consensus Document on the role of multi-modality imaging for the evaluation of patients with atrial fibrillation. Eur Heart J Cardiovasc Imaging. 2016;17(4):355-83. https://doi.org/10.1093/ehjci/jev354.

79. Kamel H, Bartz TM, Elkind MSV, Okin PM, Thacker EL, Patton $\mathrm{KK}$, et al. Atrial cardiopathy and the risk of ischemic stroke in the CHS (cardiovascular health study). Stroke. 2018;49(4):980-6. https://doi.org/10.1161/strokeaha.117.020059.

80. Diener HC, Sacco RL, Easton JD, Granger CB, Bernstein RA, Uchiyama $\mathrm{S}$, et al. Dabigatran for prevention of stroke after embolic stroke of undetermined source. N Engl J Med. 2019;380(20): 1906-17. https://doi.org/10.1056/NEJMoa1813959.

81. Hart RG, Sharma M, Mundl H, Kasner SE, Bangdiwala SI, Berkowitz SD, et al. Rivaroxaban for stroke prevention after embolic stroke of undetermined source. N Engl J Med. 2018;378(23):2191-201. https://doi.org/10.1056/ NEJMoa1 802686

82. Yong JH, Thavorn K, Hoch JS, Mamdani M, Thorpe KE, Dorian $\mathrm{P}$, et al. Potential cost-effectiveness of ambulatory cardiac rhythm monitoring after cryptogenic stroke. Stroke. 2016;47(9):2380-5. https://doi.org/10.1161/strokeaha.115.011979.

83. Friberg L, Rosenqvist M, Lindgren A, Terent A, Norrving B, Asplund K. High prevalence of atrial fibrillation among patients with ischemic stroke. Stroke. 2014;45(9):2599-605. https://doi. org/10.1161/STROKEAHA.114.006070.

84. Ahmed N, Audebert H, Turc G, Cordonnier C, Christensen H, Sacco S, et al. Consensus statements and recommendations from 
the ESO-Karolinska Stroke Update Conference, Stockholm 11-13 November 2018. European stroke journal. 2019;4(4):307-17. https://doi.org/10.1177/2396987319863606.

85. Lang RM, Badano LP, Mor-Avi V, Afilalo J, Armstrong A, Ernande L, et al. Recommendations for cardiac chamber quantification by echocardiography in adults: an update from the American Society of Echocardiography and the European Association of Cardiovascular Imaging. Eur Heart J Cardiovasc Imaging. 2015;16(3):233-70. https://doi.org/10.1093/ehjci/ jev014.

86. Poli S, Diedler J, Hartig F, Gotz N, Bauer A, Sachse T, et al. Insertable cardiac monitors after cryptogenic stroke-a risk factor based approach to enhance the detection rate for paroxysmal atrial fibrillation. Eur J Neurol. 2016;23(2):375-81. https://doi.org/10. 1111/ene. 12843

87. Healey JS, Gladstone DJ, Swaminathan B, Eckstein J, Mundl H, Epstein AE, et al. Recurrent stroke with rivaroxaban compared with aspirin according to predictors of atrial fibrillation: secondary analysis of the NAVIGATE ESUS randomized clinical trial. JAMA Neurol. 2019;76(7):764-73. https://doi.org/10.1001/ jamaneurol.2019.0617.

88. Mor-Avi V, Yodwut C, Jenkins C, Kuhl H, Nesser HJ, Marwick $\mathrm{TH}$, et al. Real-time 3D echocardiographic quantification of left atrial volume: multicenter study for validation with CMR. JACC Cardiovasc Imaging. 2012;5(8):769-77. https://doi.org/10.1016/j. jcmg.2012.05.011.

89. Tsang TS, Gersh BJ, Appleton CP, Tajik AJ, Barnes ME, Bailey $\mathrm{KR}$, et al. Left ventricular diastolic dysfunction as a predictor of the first diagnosed nonvalvular atrial fibrillation in 840 elderly men and women. J Am Coll Cardiol. 2002;40(9):1636-44. https://doi.org/10.1016/s0735-1097(02)02373-2.

90. Vasan RS, Larson MG, Levy D, Galderisi M, Wolf PA, Benjamin EJ. Doppler transmitral flow indexes and risk of atrial fibrillation (the Framingham Heart Study). Am J Cardiol. 2003;91(9):1079 83. https://doi.org/10.1016/s0002-9149(03)00152-8.

91. Kawakami H, Ramkumar S, Pathan F, Wright L, Marwick TH. Use of echocardiography to stratify the risk of atrial fibrillation: comparison of left atrial and ventricular strain. European heart journal cardiovascular Imaging. 2019. doi:https://doi.org/10. 1093/ehjci/jez240. Study on a large cohort of cryptogenic stroke patients demonstrating the incremental value of LA and LV strain analyses over established echocardiographic parameters for the prediction of incident AF.

92. Pathan F, Sivaraj E, Negishi K, Rafiudeen R, Pathan S, D'Elia N, et al. Use of atrial strain to predict atrial fibrillation after cerebral ischemia. JACC Cardiovasc Imaging. 2018;11(11):1557-65. https://doi.org/10.1016/j.jcmg.2017.07.027.

93. Olsen FJ, Christensen LM, Krieger DW, Hojberg S, Host N, Karlsen FM, et al. Relationship between left atrial strain, diastolic dysfunction and subclinical atrial fibrillation in patients with cryptogenic stroke: the SURPRISE echo substudy. Int J Cardiovasc Imaging. 2019;36:79-89. https://doi.org/10.1007/s10554-01901700-y.

94. Kuppahally SS, Akoum N, Burgon NS, Badger TJ, Kholmovski EG, Vijayakumar S, et al. Left atrial strain and strain rate in patients with paroxysmal and persistent atrial fibrillation: relationship to left atrial structural remodeling detected by delayedenhancement MRI. Circulation Cardiovascular imaging. 2010;3(3):231-9. https://doi.org/10.1161/circimaging.109. 865683 .

95. Allessie M, Ausma J, Schotten U. Electrical, contractile and structural remodeling during atrial fibrillation. Cardiovasc Res. 2002;54(2):230-46. https://doi.org/10.1016/s0008-6363(02) $00258-4$.
96. Leung M, Abou R, van Rosendael PJ, van der Bijl P, van Wijngaarden SE, Regeer MV, et al. Relation of echocardiographic markers of left atrial fibrosis to atrial fibrillation burden. Am J Cardiol. 2018;122(4):584-91. https://doi.org/10.1016/j.amjcard. 2018.04.047.

97. Muller P, Hars C, Schiedat F, Bosche LI, Gotzmann M, Strauch J, et al. Correlation between total atrial conduction time estimated via tissue Doppler imaging (PA-TDI Interval), structural atrial remodeling and new-onset of atrial fibrillation after cardiac surgery. J Cardiovasc Electrophysiol. 2013;24(6):626-31. https://doi. org/10.1111/jce.12084.

98. Muller P, Ivanov V, Kara K, Klein-Wiele O, Forkmann M, Piorkowski $\mathrm{C}$ et al. Total atrial conduction time to predict occult atrial fibrillation after cryptogenic stroke. Clin Res Cardiol. 2017;106(2):113-9. doi:https://doi.org/10.1007/s00392-0161029-2. The authors evaluated the use of the PA-TDI for prediction of incident AF in cryptogenic stroke patients with an insertable cardiac monitor.

99. Sieweke JT, Biber S, Weissenborn K, Heuschmann PU, Akin M, Zauner F, et al. Septal total atrial conduction time for prediction of atrial fibrillation in embolic stroke of unknown source: a pilot study. Clin Res Cardiol. 2019;109:205-14. https://doi.org/10. 1007/s00392-019-01501-2.

100. De Vos CB, Weijs B, Crijns HJ, Cheriex EC, Palmans A, Habets $\mathrm{J}$, et al. Atrial tissue Doppler imaging for prediction of new-onset atrial fibrillation. Heart. 2009;95(10):835-40. https://doi.org/10. 1136/hrt.2008.148528.

101. Lupercio F, Carlos Ruiz J, Briceno DF, Romero J, Villablanca PA, Berardi C, et al. Left atrial appendage morphology assessment for risk stratification of embolic stroke in patients with atrial fibrillation: a meta-analysis. Heart Rhythm. 2016;13(7):1402-9. https:// doi.org/10.1016/j.hrthm.2016.03.042.

102. Ohya Y, Osaki M, Fujimoto S, Jinnouchi J, Matsuki T, Mezuki S, et al. Usefulness of transesophageal echocardiography for predicting covert paroxysmal atrial fibrillation in patients with embolic stroke of undetermined source. Cerebrovasc Dis Extra. 2019;9(3):98-106. https://doi.org/10.1159/000502713.

103. Yoo J, Song D, Baek JH, Kim YD, Nam HS, Hong GR, et al. Poor outcome of stroke patients with atrial fibrillation in the presence of coexisting spontaneous Echo contrast. Stroke. 2016;47(7):1920 2. https://doi.org/10.1161/STROKEAHA.116.013351.

104. Powers WJ, Rabinstein AA, Ackerson T, Adeoye OM, Bambakidis NC, Becker K, et al. Guidelines for the early management of patients with acute ischemic stroke: 2019 update to the 2018 guidelines for the early management of acute ischemic stroke: a guideline for healthcare professionals from the American Heart Association/American Stroke Association. Stroke. 2019;50(12):e344-418. https://doi.org/10.1161/str. 0000000000000211.

105. Saric M, Armour AC, Arnaout MS, Chaudhry FA, Grimm RA, Kronzon I, et al. Guidelines for the use of echocardiography in the evaluation of a cardiac source of embolism. J Am Soc Echocardiogr. 2016;29(1):1-42. https://doi.org/10.1016/j.echo. 2015.09.011.

106. Boulanger JM, Lindsay MP, Gubitz G, Smith EE, Stotts G, Foley $\mathrm{N}$, et al. Canadian stroke best practice recommendations for acute stroke management: prehospital, emergency department, and acute inpatient stroke care, 6th edition, update 2018. Int J Stroke. 2018;13(9):949-84. https://doi.org/10.1177/1747493018786616.

Publisher's Note Springer Nature remains neutral with regard to jurisdictional claims in published maps and institutional affiliations. 